\title{
Impactos Causados pelos Resíduos Sólidos do Gesso no Polo Gesseiro de Trindade- PE
}

\author{
Antônio José dos Santos ${ }^{1}$, Cyro Ribeiro de Alencar Araújo², Francisco Lopes da Silva ${ }^{3}$, \\ Lucimara Araújo Campos Alexandre 4
}

\begin{abstract}
Resumo: O município de Trindade- PE tem se mostrado como uma referência no polo gesseiro do Araripe, promovendo o crescimento do seu município, região e Estado de Pernambuco, por seu potencial gesseiro, que vem crescendo a cada dia. Porém esse crescimento tem sua contribuição negativa, por criar um alto acúmulo de resíduos sólidos, que não tem uma destinação adequada prejudicando a população em questões relacionadas ao meio ambiente e problemas à saúde da comunidade. Diante desse crescimento exagerado de resíduos sólidos surgiram alguns questionamentos quanto ao destino correto desses resíduos e se de fato esses tem afetado a população de Trindade - PE. Nesse sentido o trabalho em questão objetivou descrever o impacto causado pelos resíduos sólidos do gesso, no polo gesseiro de Trindade/PE. Tendo como objetivos específicos; avaliar a destinação dos resíduos do gesso; identificar os fatores que interferem no processo de gerenciamento dos resíduos sólidos do gesso; descrever o impacto que a má destinação do gesso pode acarretar para a população exposta. O método de estudo aplicado foi o qualitativo, onde teve como fonte de pesquisa coleta de dados através de pesquisa bibliográfica e um questionário de múltipla escolha semiestruturado, formado por 10 questões semi-estruturadas elaboradas de forma seqüencial, sistemática e disposta em itens sendo que foram divididas em dois blocos contendo questões abertas e fechadas, além de anexo de imagens referente ao tema. As entrevistas aconteceram entre os dias 25 a 30 do mês de julho de 2017 e foram entrevistadas 80 pessoas no município de Trindade- PE. O estudo mostrou que a maioria das pessoas que moram próximos as fábricas sofrem com a poeira do gesso e que foram hospitalizadas 67 pessoas entre janeiro de 2016 a junho de 2017 com possíveis casos de doenças respiratórios relacionados aos resíduos do gesso no município. Além de problemas referentes ao meio ambiente quanta vegetação, solo, ar que tem sido contaminado pelos resíduos. Das 80 pessoas entrevistadas a maioria acha que a solução para esse problema é a reciclagem aliada à participação do poder público e empresas do setor gesseiro. Enquanto para o poder público e setor gesseiro essa ainda é questão que requer mais estudo, recursos tecnológicos, financeiros e conscientização de todos. Nesse sentido o trabalho se apresenta como uma forma de trazer opções de como lidar com esse problema e possíveis soluções quanto ao destino adequado dos resíduos sólidos do gesso.
\end{abstract}

Palavras-chaves: Resíduos sólidos; impactos a saúde; meio ambiente; indústria do gesso.

\section{Impacts Caused by Solid Gypsum Residues at Polo Gesseiro of Trindade in PE}

\begin{abstract}
The municipality of Trinity-PE has been shown as a reference in the plasterer do Araripe, promoting the growth of your city, region and State of Pernambuco, by your potential Cadbury, which is growing every day, but this growth has your negative contribution, by creating a high accumulation of solid wastes, which does not have a proper disposal damaging the population on issues related to environment and health problems in the community. This overgrowth of solid waste some questions arose as to the correct destination of such waste and if indeed, these have affected the population of Trinity-PE. In this sense, the work aimed to describe the impact

\footnotetext{
${ }^{1}$ Graduando em Administração Pública pela Universidade Federal do Vale do São Francisco, ajs_borges@ hotmail.com; ${ }^{2}$ Graduando em Administração Pública pela Universidade Federal do Vale do São Francisco, cyro.sertao@ hotmail.com; ${ }^{3}$ Graduando em Administração Pública pela Universidade Federal do Vale do São Francisco, francisco.lopes.agro@ hotmail.com; ${ }^{4}$ Doutoranda em Oncologia pela Fundação Antonio Prudente - A.C.Camargo Cancer Center, possui mestrado em Saúde Materno Infantil pelo Instituto de Medicina Integral Professor Fernando Figueira (IMIP), Especialização em Programa de Saúde da Família pela Faculdade de Ciências Sociais Aplicadas (FACISA), Especialização em Educação Profissional na Área de Saúde: Enfermagem pela Escola Nacional de Saúde Pública Sergio Arouca (ENSP) e Graduação em Enfermagem pela Universidade Federal de Pernambuco (UFPE). Professora Assistente do Colegiado de Enfermagem dos módulos Estágio Supervisionado I e II e da Residência Multiprofissional em Saúde da Família da Universidade Federal do Vale do São Francisco (UNIVASF). Pesquisadora do Núcleo de Estudos em Saúde Coletiva (NESCO), lucimara.univasf@gmail.com;
} 
caused by solid wastes of plaster, in the student of Trinity/PE. Having specific objectives; evaluating the disposal of waste plaster, Identify the factors that interfere in the process of management of solid residues of plaster; describe the impact that poor allocation of plaster may cause to the population exposed. The study method applied was the qualitative, where he had as a source of research data collection through literature search and a multiple choice questionnaire semi structured, consisting of 10 questions drawn up sequentially, semi-structured and willing on items which were divided into two blocks containing open and closed questions, in addition to annex of images for the theme. The interviews took place between 25 to 30 of July 2017 and 80 people were interviewed in the municipality of Trinity-PE. The study showed that most of the people who live near factories suffering with plaster dust and hospitalized 67 people between January and June 20162017 with possible cases of respiratory ailments related to the gypsum waste in the municipality. In addition to problems related to the environment, how much vegetation, soil, air has been contaminated by waste. Of the 80 people interviewed, most people think the solution to this problem is recycling combined with the participation of the public authorities and social work sector companies. As for the public authorities and social work sector that is still an issue, that requires more study, technological, financial resources and awareness of all. In this sense, the work is presented as a way to bring options of how to deal with this problem and possible solutions regarding the appropriate destination of solid waste of gypsum.

Keywords: Solid waste; health; environmental impacts; the gypsum industry.

\section{Introdução}

O gesso é uma substância que se define como um aglomerante de origem mineral, obtida através da calcinação de gipsita constituída predominantemente de sulfato de cálcio hidratado (CaSO4.2H2O) conhecido como gesso natural (BAUER, 2001), sendo classificado como um ligante hidrófilo aéreo que possui propriedades aglomerantes ao ser misturado com água e outros aditivos, formando uma pasta homogênea que endurece em poucos minutos, perdendo a consistência e ganhando viscosidade (COUTINHO,2006).

O gesso possui plasticidade, homogeneidade e estabilidade volumétrica. Sendo um material amplamente utilizado na construção civil, assim como na fabricação de pré moldados (placas, blocos) presta uma grande variedade de aplicações como: peças de sancas, molduras para tetos, colunas de placas, fixação de forros ceramista, fundidor, decorador, revestimento de paredes, isolamento térmico e acústico. Por conta de sua capacidade de endurecimento rápido na fase de sua aplicação provoca um acúmulo considerável de resíduos nas construções civis, fabricas de pré- moldados e calcinação (INDEBRAS, 2011). 
Aliado ao desenvolvimento de novas tecnologias, o gesso tem demandado mais procura o que desencadeou uma excessiva geração de resíduos e com ele um problema de como administrar locais apropriados para descarte ou reutilização desse material (SindusCom, 2005). De acordo com Pucci (2006), existem poucas áreas regularizadas, o que faz com que agregue dificuldade ao processo de destinação adequada, sendo descartados em terrenos baldios, aterros sanitários, margens e rios. Estima-se que cerca de 5\% do gesso é transformado em resíduos durante a construção civil, $4 \%$ de perda por fabricação de pré-moldados e $35 \%$ quando aplicado como revestimento em alvenaria (SINDUSGESSO, 2006).

A destinação inadequada dos resíduos do gesso acarreta problemas como: degradação das áreas de manancial e de proteção permanente; proliferação de agentes transmissores de doença; assoreamento de rios e córregos; obstrução do sistema de drenagem, tais como galerias, sarjetas; ocupação de vias e logradouros públicos; problemas respiratórios; degradação da paisagem urbana e rural, contaminação de solo e lençóis freáticos e do ar dióxido de carbono (SindusCom, 2005).

Diante dessa realidade, o gerenciamento dos resíduos se apresenta como uma saída para minimizar a partir de projetos elaborados e implantados pelos geradores, a fim de estabelecer os procedimentos necessários para o manejo e destinação ambientalmente adequados dos resíduos. A resolução CONAMA 431/1, que alterou e classificou o resíduo como reciclável, permite quer os geradores tenham o gerenciamento como forma de tentar resolver esse problema, mas que precisará envolver aspectos administrativos, gerenciais, econômicos e desempenho, considerando aspectos tecnológicos e operacionais (LIMA,2003).

Segundo Lima (2009), no seu guia para elaboração de projetos de gerenciamento de resíduos, devem atender algumas fases como: planejamento, de caracterização, de triagem ou separação, de acondicionamento, armazenamento, de transporte, de reutilização e reciclagem, de remoção dos canteiros e destinação final. Para que os planos ou projetos venham obter sucesso os geradores e poder público, sociedade, empresas, prefeitura, governos estaduais e federais devem ter uma responsabilidade compartilhada e seguir a Lei $\mathrm{n}^{\circ} 12.305$, denominada Política Nacional de Resíduos Sólidos -PNRS, que em seu Art. 1 institui a s diretrizes relativa a gestão integrada e ao gerenciamento desses resíduos, incluindo os perigos, além de estabelecer responsabilidades e sanções aos responsáveis. 
Nesse contexto, considerando que a cidade de Trindade - PE esta localizada em uma área riquíssima em gipsita, que vem sendo explorada há décadas sem levar em conta a sua biodiversidade e que nessa região o gesso é amplamente utilizado nas fábricas de placas e blocos, gerando um grande acúmulo de resíduos, e que por muitas vezes não tem o devido tratamento ou destino adequado, gerando inúmeros problemas para o meio ambiente e à saúde público, esse trabalho terá como objetivo principal descrever o impacto causado pelos resíduos sólidos do gesso, no polo gesseiro de Trindade/PE. Tendo como objetivos específicos; Avaliar a destinação dos resíduos do gesso; Identificar os fatores que interferem no processo de gerenciamento dos resíduos sólidos do gesso; Descrever o impacto que a má destinação do gesso pode acarretar para a população exposta. Para isso foi adotado o método de pesquisa qualitativo do tipo descritivo no município de Trindade/PE, cujos resultados poderão contribuir para a elaboração de políticas locais no que se refere ao destino adequado desses resíduos no município, promovendo assim saúde ambiental e coletiva.

\section{História do Gesso no Município de Trindade - PE}

No município de Trindade/PE, a gipsita começou a ser comercializada nos anos 50 como pedra bruta. Com a implantação da primeira fábrica de gesso calcinado, nos anos 70 , deu impulso para o surgimento de várias indústrias nos anos 80 aumentando a produtividade assim como o crescimento da cidade. O município está situado no polo gesseiro do Araripe localizado no extremo Oeste de Pernambuco e abrangem as cidades de Araripina, Bodocó, Ipubi, Trindade e Ouricuri, sendo responsável pela produção de $97 \%$ do gesso consumido no país. O setor movimenta cerca de R \$ 1,4 milhões por ano, gerando 13,8 mil empregos diretos e 69 mil empregos indiretos no estado de Pernambuco resultante a atuação de 42 minas de gipsita, 174 indústrias de calcinação e cerca de 750 indústrias de pré- moldados (SINDUSGESSO, 2013).

A região fornece cinco milhões de toneladas de gesso anualmente, tendo uma reserva de gipsita estimada em 1,2 bilhões de toneladas, sendo o quinto volume do mundo, além de ser considerada a melhor em qualidade, com teor de pureza variando de 88 a $98 \%$. Dentro dessa cadeia produtiva a cidade de Trindade/PE tem se destacado nas últimas décadas por sua produção do gesso extraído através de gipsita bruta, sendo considerada, atualmente, a capital 
Estadual do gesso, sob a lei Estadual $n^{\circ} 15.115 / 2013$. A gipsita bruta é transportada para as indústrias de calcinação de gesso, que por sua vez vendem a produção para construção civil, indústrias de pré-moldados, artesanatos, gerando assim uma grande fonte de renda para o município e região, fazendo parte da cadeia produtiva do sertão do Araripe em geração de empregos diretos e indiretos, concentrando o maior número de empresas no setor (SINDUSGESSO, 2013).

\section{Normas Sobre os Residuos Sólidos do Gesso}

Os resíduos sólidos são classificados de acordo com suas características físicas (secos e molhados) em relação a sua composição química (orgânica e inorgânica); quanto a sua origem (domiciliares, comerciais, serviços públicos, hospitalar, agrícola, industrial...). Em 2004 foi publicada segundo a Associação Brasileira de Normas Técnicas (ABNT) a nova versão da norma NBR 10.004-Resíduos sólidos. Essa norma tem como propósito fazer a distinção dos resíduos sólidos quanto aos seus riscos ao meio ambiente e a saúde pública. Essa norma versão classifica os resíduos em três classes distintas: classe I estão os (perigosos), Classe II estão os (não-inertes) a classe III estão os (inertes). Dessa forma ficaria melhor o gerenciamento de forma adequada desses resíduos, quanto ao uso e destino final (ABNT, 2004).

Segundo a Resolução (CONAMA) n431/2011 que alterou o art. $3^{\circ}$ da Resolução $n^{\circ}$ $307 / 20002$ que entrou em vigor em 25/05/2011, estabelece uma nova classificação para o gesso oriundo da construção civil, classificando-o como resíduo reciclável. Passando a vigorar a seguinte redação, em seu artigo $3^{\circ}$, sobre a Classe B e C dispõem que a Classe B: são os resíduos recicláveis para outras definições como; plásticos, papel, papelão, metais, vidros, madeiras e gesso. Classe C; são os resíduos recicláveis para os quais não foram desenvolvidas tecnologias ou aplicações economicamente viáveis que permitem a sua reciclagem ou recuperação.

O governo Federal, promulgou a Lei $\mathrm{n}^{\mathrm{o}}$ 12.305, em 2 de Agosto de 2010, denominada Política Nacional de Resíduos Sólidos - PNRS, essa lei enfatiza a responsabilidade compartilhada, envolvendo a sociedade, empresas, prefeituras e governos 
estaduais e federais, que em seu Art. $1^{\circ}$ a PNRS sobre seus princípios, objetivos e instrumentos, bem como sobre as diretrizes relativas à gestão integrada e ao gerenciamento desses resíduos, incluindo os perigosos, e responsabilidades dos gerenciadores e do poder público e as sanções aplicáveis a cada um dos que foram mencionados. Outra instrução normativa é do CPRH- Agência Estadual de Meio Ambiente e Recursos Hídricos no in-0042006.Disciplina o art. 20 da Lei $n^{\circ}$ 12.008, 01 de junho de 2001, que dispõem sobre a Política Estadual de Resíduos Sólidos, criando critérios para apresentação de Plano para Gerenciamento de Resíduos sólidos Industriais (PGRSI), e aprova o termo de referência para apresentação do PGRSI.

\section{IMPACTOS AMBIENTAIS DAS ATIVIDADES DO GESSO}

Em seu Art. $2^{\circ}$ a Política Nacional do meio Ambiente assegura em seu capitulo, que terá por objetivo a preservação, melhoria e recuperação da qualidade ambiental propicia a vida, a compatibilização do desenvolvimento econômico-social com a preservação da qualidade do meio ambiente e do equilíbrio ecológico. Em seu art. $9^{\circ}$ da Política Nacional do meio ambiente disposta na Lei n 6.938/1981 institui o estabelecimento de padrões de qualidade ambiental, zoneamento ambiental, avaliação de impactos ambientais, licenciamento e revisão de atividades efetivas ou potencialmente poluidoras. Caso essas medidas necessárias não forem cumpridas quanto à preservação ou correção da degradação ambiental, serão estabelecidas penalidades disciplinares ou compensatórias.

Dentre alguns problemas relacionados se destacam: contaminação da água, solo, diminuição da vegetação caatinga, poluição de rios, via pública, poluição do ar, contaminação do lençol freático, desertificação resultando em êxodo rural, problemas de saúde dos trabalhadores e moradores locais. Segundo alguns autores (JONH; CINCOTTO, 2003; NITA et al., 2004). Os resíduos de gesso é um material determinante de contaminação constituem 
um problema de limpeza pública, pois este material apresenta limitações para disposições em aterros sanitários, onde, na ausência e oxigênio, o sulfato de gesso pode reduzido biologicamente por bactérias anaeróbias, formando três tipos de sulfatos, entre eles o sulfato de hidrogênio (H2S) denominado gás sulfídrico, que pode causar a morte se inalado em altas concentrações por seu um composto corrosivo com odor forte. O sulfato de cálcio é considerado um contaminante secundário da água por ser altamente solúvel em água libera íons de sulfato de solução que podem contaminar ao lençol freático podendo modificar aspectos da água como cor, odor e sabor. Outro problema esta relacionado à incineração de resíduos do gesso no processo de queima que libera o dióxido de enxofre apos o sulfato de gesso se converter, resultando em redução da eficiência de dispositivos alcalinos que controla a poluição atmosférica (MARVIN, 2000). Essa poluição atmosférica caracteriza-se pela presença de materiais ou formas de energia no ar que impliquem risco dano ou moléstia grave as pessoas e bens de qualquer natureza (ARÁNGUEZ e al., 2001). Segundo (FELLENBERG, 1997) A poeira atmosférica traz com ela algumas consequiências tais como: diminuição da intensidade de radiação do sol, estimada em cerca de $0,4 \%$ por ano e perdas de energia que não se refletem somente numa diminuição geral da temperatura, principalmente na velocidade e direção dos ventos.

\section{IMPACTOS A SAÚDE DA POPULAÇÃO}

Dentre os problemas, mas relacionados estão efeitos irritativos nos olhos, nas mucosas e no aparelho respiratório, além de efeitos mais sérios ou permanentes como problemas cutâneos ou crônicos dentre as doenças que podem se oriundo do gesso se destacam sangramentos nasais, irritação nos brônquios, traquéia, conjuntivite, rinite, amidalite, Pneumoconiose, Calcicosilicosis, fibrose pulmonar, principalmente problemas respiratórios (NIOSH, 2002; 1989; et al).

Segundo o estudo feito em 2003 por (MEDEIROS, M. 2003) sobre a poluição ambiental por exposição à poeira do gesso: impactos a saúde da população (Região do Araripe) apresentou que a poeira do gesso tem um impacto na saúde das pessoas exercendo uma ação irritante na membrana da mucosa do trato respiratório e dos olhos, desencadeando afecções, chegando a 30\% dos casos de internações causado por problemas respiratórios na região. Outro estudo em 2003 por (MEDEIROS, M. et al., 2003) sobre "a saúde no contexto 
do pólo gesseiro de Araripina - PE" apresentou como resultado que em domicílios a presença da poeira dentro de casa se mostrou presente com queixas de irritação dos olhos, irritação da pele, cansaço e tosse.

\section{Meios de Destinar os Resíduos Sólidos do Gesso}

Diante de tal realidade existem atualmente algumas formas de destinar os resíduos sólidos, dentre os mecanismos dispostos estão: Reciclagem; coleta seletiva, aterro, beneficiamento, reaproveitamento, reutilização. Que devem ser elaborados por um projeto de gerenciamento de resíduos sólidos. O gesso pode ser reutilizado na agricultura, como aditivos, fertilizante e condicionador, na indústria de cimento e indústria de transformação do gesso.

\section{Métodos e Materiais}

O trabalho em questão tratou de um estudo qualitativo, onde teve como fonte de pesquisa coleta de dados através de pesquisa bibliográfica e um questionário de múltipla escolha semi estruturado, que teve como características questionamentos básicos relacionado ao tema da pesquisa, a fim de possibilitar a discrição compreensão e classificação do objeto de estudo.

O questionário foi formado por 10 questões semi-estruturadas elaboradas de forma seqüencial, sistemática e disposta em itens sendo que foram divididas em dois blocos contendo questões abertas e fechadas que foi conduzido pelo entrevistador com questionamentos destinados aos entrevistados com total imparcialidade, bom senso. As 10 perguntas foram divididas em etapas; primeiro bloco (questões 1 a 5) direcionada a Secretaria de saúde, Secretaria de meio ambiente e Urbanismo. O segundo bloco (questões de 6 a 10) consistiu em perguntas direcionadas; ao Poder Executivo, poder Legislativo, donos de fabricas, SINDUGESSO, CEREST e moradores.

As entrevistas aconteceram entre os dias 25 a 30 do mês de Julho 2017, com visitas as indústrias do gesso, área urbana e zona rural do município de Trindade/PE, tendo como 
entrevistados: representantes de empresas do setor gesseiro, poder Executivo e Legislativo do município, secretaria de saúde, secretaria do meio ambiente, SIDUGESSO - Sindicato da indústria do Gesso do Estado de Pernambuco, CEREST- Centro de Referência a Saúde do Trabalhador; trabalhadores das fábricas e moradores que residem perto de fábricas de gesso.

\section{Resultados e Discusões}

Entre os dias 25 a 30 do mês de Julho foram entrevistados 80 pessoas no município de Trindade- PE através de um questionário com 10 questões direcionado ao tema da pesquisa "Impactos dos resíduos do gesso no município". Diante da pergunta. Qual seria a melhor forma de destinação dos resíduos sólidos do gesso no município? Aterro sanitário, Reciclagem, Gerenciamento, Beneficiamento, dos 80 entrevistados, 65 responderam que a melhor forma de destinação seria a reciclagem 10 optaram por gerenciamento e 5 não souberam opinar. Em relação à atual forma de destinação dos resíduos sólidos no município, dos 80 entrevistados 69 discordam 2 concordam e 9 discordam totalmente. Em relação à participação da indústria na administração dos resíduos 47 acham ruim a participação, 15 acham regular, 9 péssimos, 9 acham bom. Quanto à participação do poder público, 39 acham regular 15 péssimos, 16 bons e 10 não quiseram opinar.

As perguntas relacionadas à secretaria de saúde e CEREST- Centro de Referência a saúde do trabalhador. Foi à seguinte; existem doenças relacionadas aos resíduos do gesso no município? Segundo a secretaria de saúde do município de Trindade - PE foram internadas 67 pessoas por infecções respiratórias de janeiro de 2016 até junho de 2017, sendo que 57 formam em 2016. O valor gasto com essas internações foi de 31.472,06. Valor médio por cada internação 539,77 Segundo a secretaria asmas, pneumonia, irritação nos olhos, conjuntivite, tosse, sangramento nasal pode ter uma relação com o gesso, porém faltam mais estudos que comprovem de fato essas questões. Segundo o especialista o doutor Agamenon Braz da Penha ex- medico do trabalho de Araripina-PE; disse que durante os 20 anos que trabalhou como medico do trabalho não constatou nem um tipo de doença que tenha sido provocada pelo contato direto com o gesso.

E visto que falta mais estudo que venham a comprovar essas relações. Porém com a poluição da poeira do gesso muitos se queixam de sintomas respiratórios principalmente 
quem trabalha nas fábricas e moradores próximos a fabricas ou a lixões contendo os resíduos do gesso. Segundo o CEREST existem problemas respiratórios que afetam os trabalhadores, porém não existem estudos mais específicos que comprovem essa relação no município de Trindade - PE.

Quanto às medidas tomadas o CEREST orienta as empresas a distribuir EPI para proteção individual para manuseio nas fabricas e diminuir os riscos provocados pela poeira do gesso. Em perguntas direcionadas a secretaria de meio ambiente e urbanismo; existe uma medida de gerenciamento de resíduos em andamento? Segundo a secretaria de meio ambiente existem leis pertinentes, que as indústrias têm que segui a fim de minimizar impactos dos resíduos do gesso, porém faltam mais fiscalização e políticas de incentivo e mais conscientização dos que produzem matérias oriundas do gesso.

Diante das perguntas aos donos de fabricas de pré-moldados, muitos disseram que não tem licença ambiental e nem tão pouco algum laudo ambiental, mais que tentam da melhor forma da o destino adequado aos resíduos de acordo com a realidade local, uma vez que isso requer um gasto com maquinas, tecnologias e mão de obra, pois segundo alguns não dependem só deles mais de outros departamentos e faltam políticas voltadas para o gerenciamento através de parcerias com o setor privado e o público a fim de diminuir os problemas causados pelos resíduos do gesso.

A cidade de Trindade - PE a princípio as políticas de combate a esse problema não tem sido eficazes sem atender o que é previsto por lei da resolução $n^{\circ} 307$ do CONAMA quanto ao destino dos resíduos sólidos do gesso, pois os mesmo são misturados a lixo orgânico e queimados a céu aberto ou jogados em vias públicas ou em áreas rurais contaminando o solo e lençóis freáticos, além de reprodução de insetos, roedores e microorganismo transmissores de doenças causando danos a população.

Dentre os problemas atuais estão; resíduos jogados perto de vegetação matando a caatinga, provocando erosão e desertificação, jogada em estradas, ruas, esgotos, perto das casas, riachos, além da poeira do gesso que afeta diretamente a população que mora perto dos locais das fabricas ou onde são jogados os resíduos, sem contar na queima dos resíduos resultado em uma fumaça com teor de toxicidade.

Segundo a secretaria foi feito audiências públicas com outros órgãos mais que não tem nem um projeto em andamento, atualmente os serviços prestados envolve os seguintes 
Id on Line Revista Multidisciplinar e de Psicoloqia

Id on Line Multidisciplinary and Psycology Journal

serviços: coleta de lixo domiciliar; remoção de lixo pesado; remoção de resíduos/entulho por meio de caminhão caçamba, através da secretaria de urbanismo da cidade.

Para ilustrar melhor a situação as imagens a segui mostram um pouco sobre o destino dos resíduos atualmente:

Foto 1- Essa imagem mostra como tem sido ultimamente o destino dos resíduos em alguns pontos do município. Esses foram jogados as margens do rio Trindade.

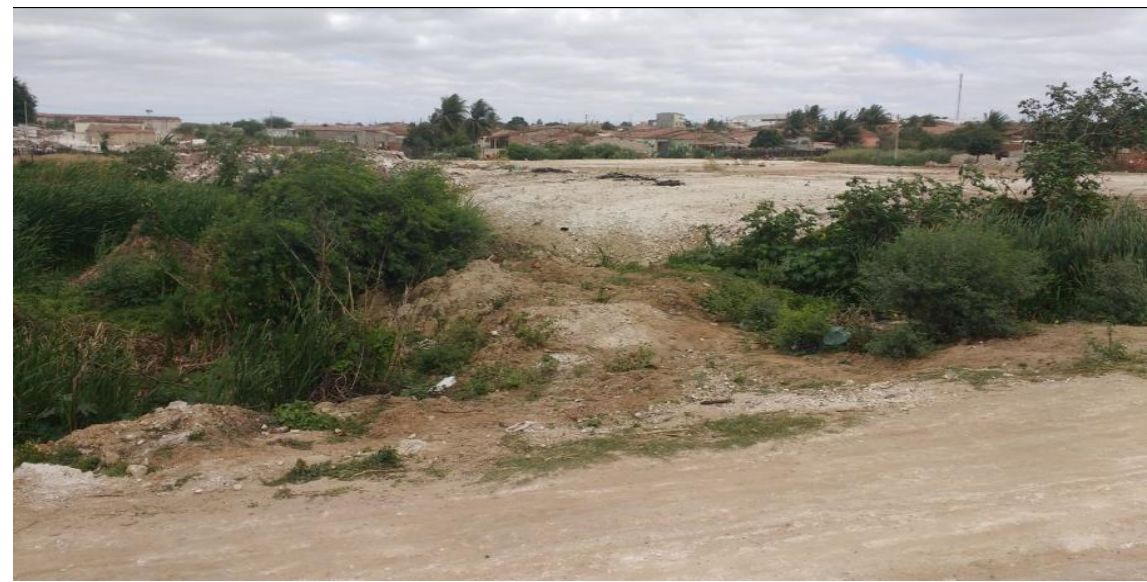

Fonte: Coletada pelos autores. 2017.

Foto 2- Essa retrata uma realidade presente no município, onde os resíduos são descartados próximos a rede de esgoto e córregos podendo afetar diretamente o ciclo de água e esgoto nos períodos de chuvas.

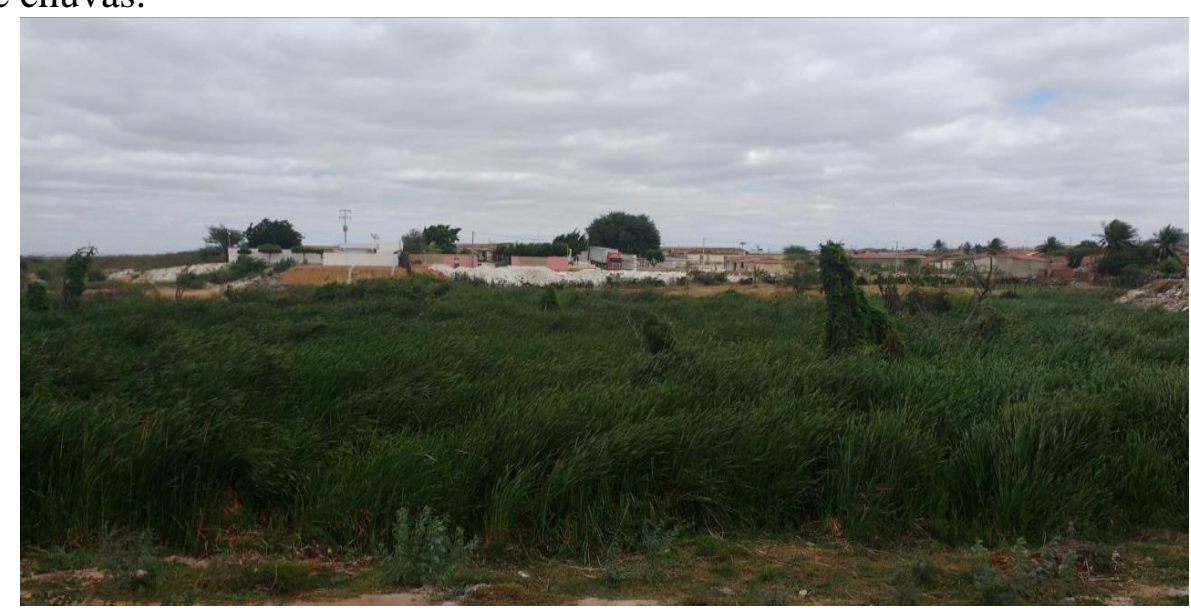

Fonte: Coletada pelos autores. 2017. 
Foto 3 - Outro problema são os resíduos jogados nas proximidades das estradas, provocando poeira, afetando a vegetação e erosão do solo prejudicando a rodovia.

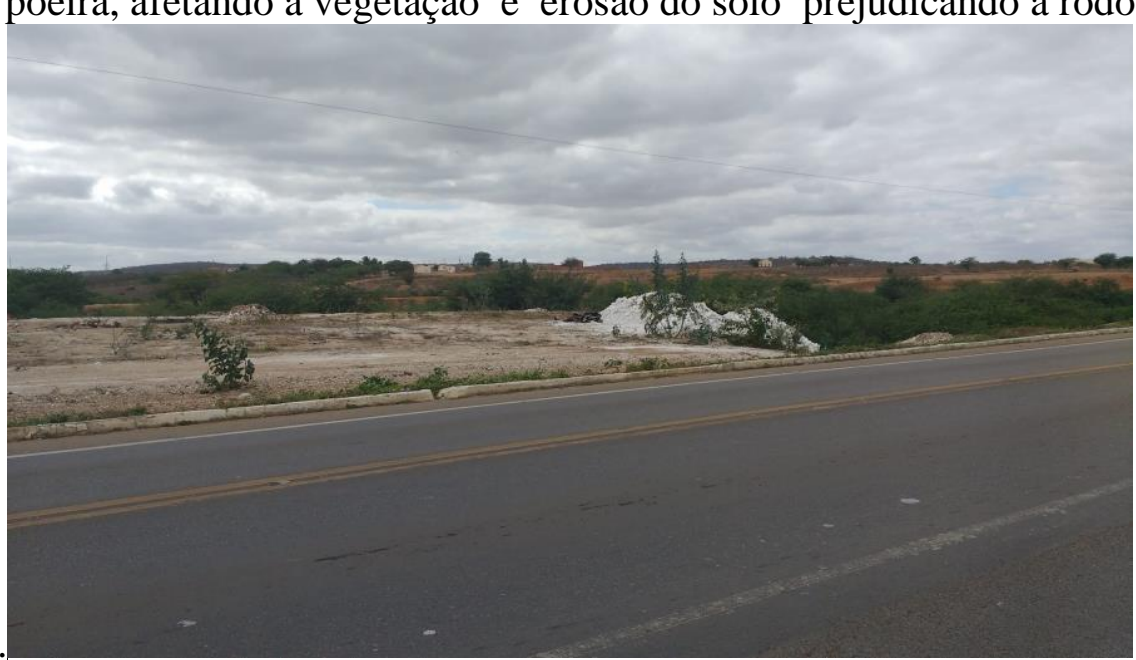

Fonte: Coletada pelos autores. 2017.

Foto 4 - A poeira e a fumaça são fontes de poluição oriundas das fabricas causando danos a saúde das pessoas e do meio ambiente. Atualmente o problema tem aumen tado devido uma crescente demanda do uso do coque um derivado do petróleo que tem substituído a lenha no processo de fabricação do gesso.

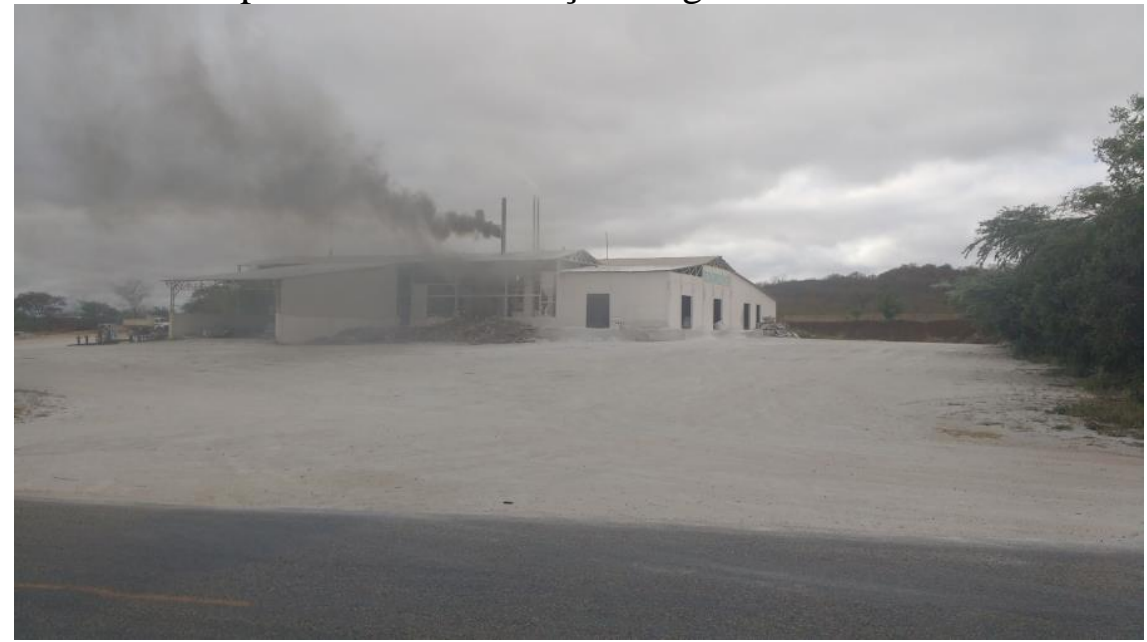

Fonte: Coletada pelos autores. 2017. 
Id on Line Revista Multidisciplinar e de Psicoloqia

Id on Line Multidisciplinary and Psycology Journal

Foto 5 - Resíduos jogados nas estradas de chão e próximo a vegetação.

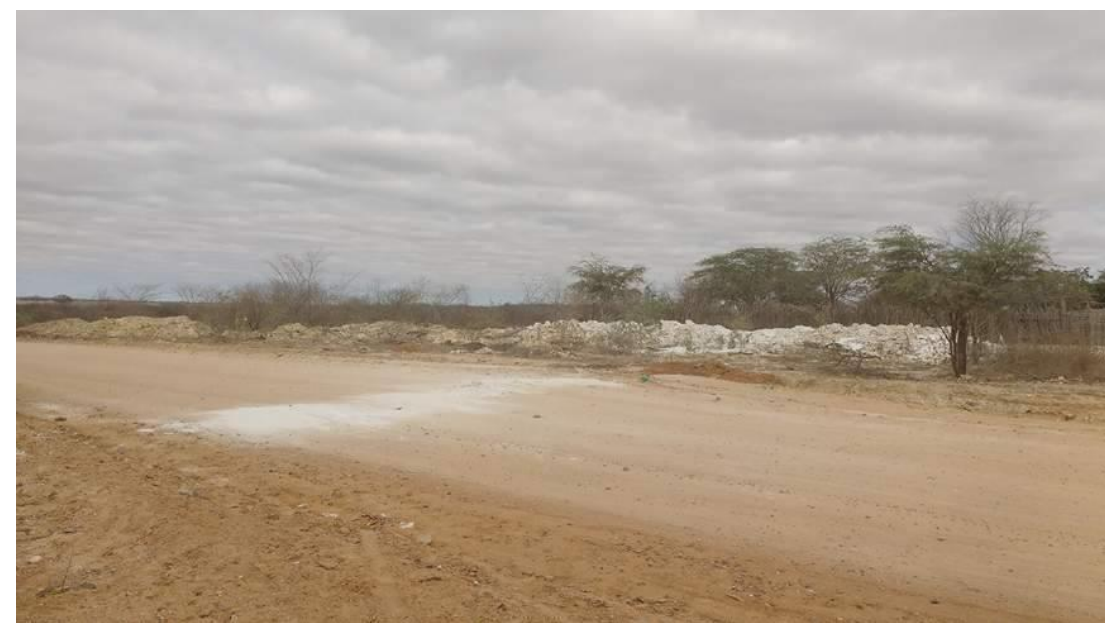

Fonte: Coletada pelos autores. 2017.

Foto - 6 Residuos jogados na caatinga.

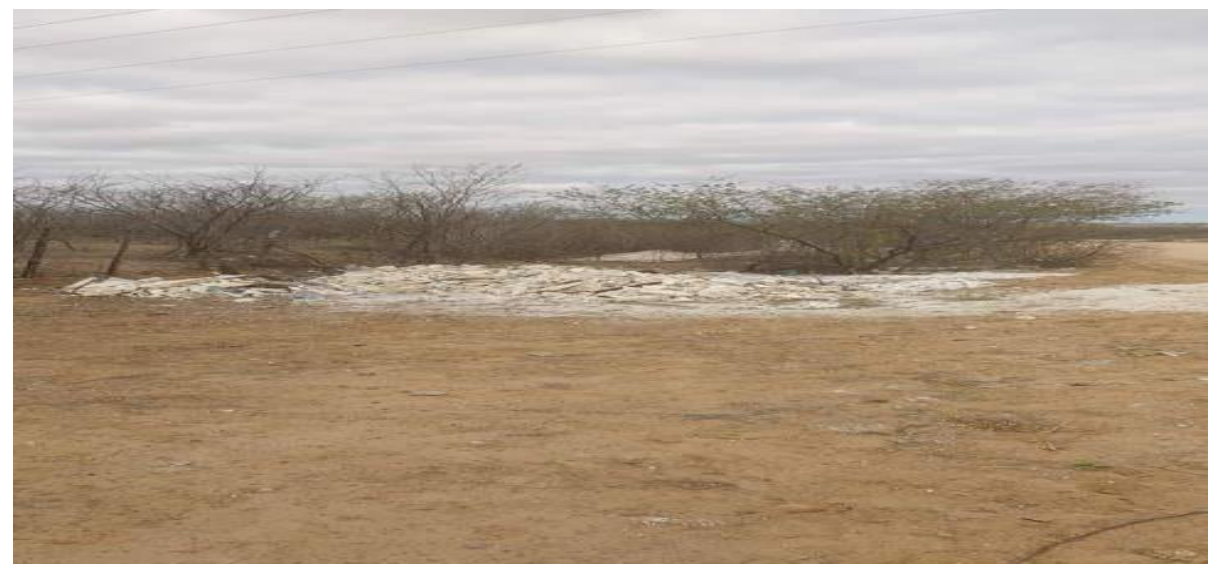

Fonte: Coletada pelos autores. 2017. 


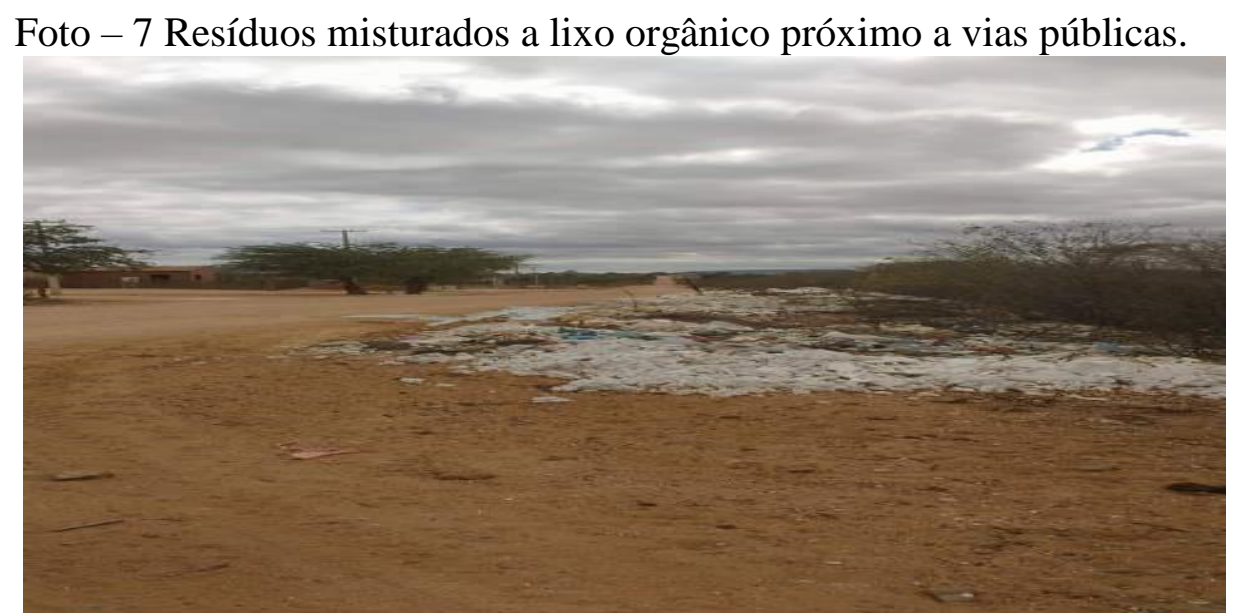

Fonte: Coletada pelos autores. 2017.

Atualmente, o poder público local tem buscado meios para minimizar o problema atendendo a população através de serviços como remoção de resíduos em vias públicas, participação de fóruns, audiências, palestras. Porém ainda é uma participação tímida perante o agravante sendo preciso um desenvolvimento de políticas publicas destinado aos problemas atuais aliados a uma participação mais efetiva da população e de donos de fabricas a fim de criar condições de destinar corretamente esses resíduos e minimize os problemas que pendura por muito tempo no município de Trindade-PE.

\section{Conclusão}

Diante da realidade atual de como gerenciar adequadamente os resíduos sólidos do gesso produzidos pelas fabricas e a busca de mecanismos que venha a minimizar os impactos dos resíduos do gesso no município. Foi visto que dos 80 entrevistados a melhor solução para o destino do gesso seria por meio da reciclagem, porém não tem nem um projeto de gerenciamento implantado no município e não há políticas públicas voltadas ao beneficiamento e reciclagem. Atualmente o gesso é reaproveitado sendo jogado para tapar buracos nas estradas, sendo aproveitado mais os resíduos do gesso para fabricação de blocos para construção civil. 
O sistema atual de limpeza das vias públicas desenvolvidos pelo poder público, consiste em remoção de resíduos e entulho através da secretaria de urbanismo, porém não tem uma coleta seletiva desses resíduos os mesmos são retirados das ruas, mas são jogados em outros locais indevidos como perto de estradas ou queimados.

Nesse sentido é preciso que seja desenvolvidos projetos junto aos donos de fabricas com o poder publico municipal, porém ainda existe certo tabu quando se fala em resíduos sólidos do gesso no município por envolver outras questões políticas ou pessoais que acaba camuflando o problema.

Se por um lado é considerada a capital do gesso, por outro lado os problemas relacionados tem se apresentado segundo a secretaria de saúde do município, como doenças do aparelho respiratório, representando um gasto financeiro aos cofres público do município, para se ter uma idéia entre janeiro de 2016 a Junho de 2017 foram gasto 31.472,06 com internações que poderiam ser reduzidos se tivesse políticas de gerenciamento adequado do gesso. Porém ainda não existam estudos mais específicos sobre a questão saúde do município, que poderiam contribuir para solucionar tais problemas ou alertar quanto aos riscos que a população estaria exposta comprometendo as gerações futuras.

Em entrevistas as pessoas que moram perto das fábricas, foram visto que um dos problemas mais relacionados aos resíduos do gesso tem sido a poeira de gesso, que segundo esses tem causado problemas a saúde das pessoas como: irritação nos olhos, asma, cansaço, problemas relacionados ao aparelho respiratório, sendo o mais relatado. Segundo a secretaria de saúde de Trindade, por ano é diagnosticado varias doenças em pessoas que moram no município, pois existe uma possível relação com a poluição da poeira do gesso com a saúde da população.

Quanto aos donos de empresas muitos tem certa preocupação, porém não vão além de suas expectativas, pois isso tem sido um problema que vem sendo debatido há anos e que não tem sido encontrada solução, uma vez que depende de recursos financeiros e alta tecnologias e muitos não estão dispostos a fazer tais investimentos, pois não tem capital suficiente ou porque não ter uma consciência ecológica o que dificulta a resolução dos problemas.

Diante de dessa realidade o trabalho em questão buscou tentar responder tais questionamentos que se rastejam por anos no município. $\mathrm{O}$ alvo do projeto na comunidade é 
melhorar as questões ambientais, econômicas e sociais chegando a um patamar de equilíbrio entre comunidade e natureza, reduzindo os resíduos do gesso no município, porém não há divulgação o suficiente e nem estudos sobre os problemas de saúde, além da falta de interesse por parte do poder público municipal, empresarial e da sociedade, quanto a medidas solidas sobre os impactos negativos que os resíduos do gesso esta trazendo para a população.

Neste contexto é visto que se torna importante a implantação de novas tecnologias para que possa ser reciclado, gerenciado, reutilizado ou reaproveitado os resíduos do gesso, para que possa contribuir com a redução ou minimizar tais problemas e com isso promover uma melhor qualidade de vida para a população com desenvolvimento sustentável garantindo um futuro melhor pra todos.

\section{Referências}

Apostila, Manual de normatização de trabalhos acadêmicos da UNIVASF/ UNIVASF-2. Ed. Petrolina, 2013.

LOPES, W. et al. Plano de Gerenciamento de Resíduos Sólidos - PGRS. Município de Florianópolis/SC, Fevereiro de 2011. Acesso em 09/09/2016.

MEDEIROS, M. et al. A saúde no contexto do pólo gesseiro de Araripina-PE. Saúde Soc.São Paulo, v.19, n,2p.358-370,2010. Acesso em 05/09/2016.

SOUZA, R. et al. Tratamento dos Resíduos de Gesso da Construção Civil: o caso das construtoras na cidade de Maceió.VII CONNEPI,. Palmas - Tocantins, 2012. Acesso em 07/09/2016.

SILVA, R. et al. Panorama do projeto de gerenciamento de resíduos da construção civil (PGRCC)-Estatuto de caso na construção do centro Administrativo do distrito Federal(CADF). Anais do IV SINGEP - São Paulo - SP - Brasil-08.09 e 10/11/2015. Acesso em 09/09/2016.

ARAÚJO, SÉRGIO. A ação do Estado e o meio ambiente no pólo gesseiro do Araripe-PE nos anos de 1990 e 2000. Rios Eletrônica - Revista Cientifica da FASETE, ano7, n, 7 dez/de 2013.

CARTAXO, GLAUBER A. A. Analise do gerenciamento dos resíduos de gesso no município de Salvador-Ba,Glauber A. A Cartaxo - Salvador, 2011.160. 
Id on Line Revista Multidisciplinar e de Psicoloqia

Id on Line Multidisciplinary and Psycology Journal

TOLOI, G.; MANZINI, E,J. Etapas de estruturação de um roteiro de entrevista e considerações encontradas durante a coleta dos dados. VIII Encontro da Associação Brasileira de Pesquisadores em Produção Especial. Londrina $5^{\mathrm{a}} 7$ de Nov/2013. Disponível em: www.uel.br/eventos/congressomultidisciplinar/pages/arquivos/anais/.../AT14-008.pdf . acesso em; $20 \mathrm{de} \mathrm{Jul/2017.}$

MANZINI, E.J. Entrevista semi-estruturada: análise de objetivos e de roteiros. In: SEMINÁRIO INTERNACIONAL SOBRE PESQUISA E ESTUDOS QUALITATIVOS, 2, 2004, Bauru. A pesquisa qualitativa em debate. Anais... Bauru: USC, 2004. CD-ROOM. ISBN:85-98623-01-6. 10p. Disponivel em: https://www.marilia.unesp.br/Home/.../Manzini _2004_entrevista_semi-estruturada.pdf. Acesso em 21 de Jul/2017.

Como citar este artigo (Formato ABNT):

SANTOS, Antônio J. dos; ARAÚJO, Cyro R. de A.; SILVA, Francisco L.da; ALEXANDRE, Lucimara A.C. Impactos Causados pelos Resíduos Sólidos do Gesso no Polo Gesseiro de Trindade- PE. Id on Line Revista Multidisciplinar e de Psicologia, 2017, vol.11, n.37, p.143-159. ISSN: 1981-1179.

Recebido: 12.08 .2017

Aceito: 14.08 .2017 